The fine weather prevailing this month and during part of September allowed me to maintain long watches for shooting stars as follows :-

$$
\begin{aligned}
& \text { September } 4 \text { watched during } 4^{\frac{1}{2}} \text { hours and saw } 37 \text { meteors. }
\end{aligned}
$$

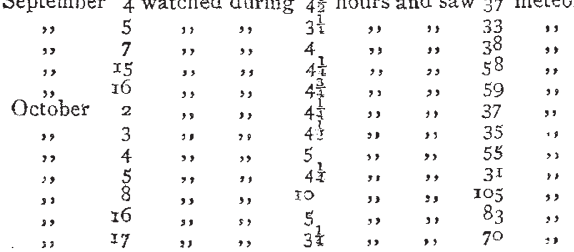

Giving an aggregate watch of 57 hours and $64 \mathrm{r}$ meteors visible for September 4-October 17 ; but this merely relates to a portion of the work, for I have only included in this list those nights when I watched for long periods together.

From these nume rous observations I was enabled to deduce many radiant points, and have selected a few of the most important :-

\begin{tabular}{|c|c|c|c|c|c|c|c|}
\hline No. & Date. & R.A. Dec. & & & o. of $\downarrow$ 's. & & $\operatorname{Max}$ \\
\hline x. & September & $8 \mathrm{r}+3^{6}$ & $\cdots$ & & meteors & & Sept. 7 and 15 \\
\hline 2. & Sept. and Oct. & $85+54$ & $\cdots$ & 26 & ", & $\cdots$ & Sept. 5 and Oct. 5 \\
\hline 3. & Sept. and Oct. & $109+3^{8}$ & $\cdots$ & 20 & ," & $\cdots$ & Octolier 8 \\
\hline 4. & Sept. and Oct. & $220+7^{8}$ & ... & 18 & , & $\cdots$ & September I 5 \\
\hline 5. & Sept. and Oct. & $60+\$ 5$ & $\ldots$ & r. & $\therefore$ & $\cdots$ & (Ociober 2.8 \\
\hline 6. & September & $37+34$ & $\cdots$ & TO & $"$ & $\cdots$ & September IO \\
\hline 7. & Sept, and Oct. & $103+12$ & ... & 27 & ," & $\cdots$ & Getober 8 \\
\hline 8. & October & $133+79$ & $\cdots$ & 22 & , & $\cdots$ & October $3-4$ \\
\hline 9 . & October & $310+77$ & $\cdots$ & 57 &, & $\cdots$ & October 34 \\
\hline ro. & October & $225+52$ & $\ldots$ & 10 & 1 , & $\cdots$ & October 2 \\
\hline Ix. & October & $x_{33}+2 x$ & $\cdots$ & is & , & $\cdots$ & Octiber is \\
\hline 12. & October T.5-20 & & ... & 57 & ," & $\ldots$ & October is \\
\hline
\end{tabular}

The last position is that of the well-known October shower, the Orionids. Several of the above radiants are probably new, and it is noteworthy that No. 8 agrees very closely with the radiant and date (R.A. $134^{\circ}, 77^{\circ}$ Dec. N., October $7+$ ) of Comet II., I825, as calculated by Prof. A. S. Tĩerschel.

Ashleydown, Bristol, October 22

W. F. DENNING

A METEOr of unusual brilliancy was seen by the passengers in the train from Exeter to Bristol, about 6.I5 I.M. yesterday. The train was at the time about two or three miles south of Weston Junction. As nearly as I could judge, the meteor made its first appearance at an altitude of about $35^{\circ}$, and $4^{\circ}$ or $5^{\circ}$ scuth of west, and moved rapidly towards the horizon almost in a vertical line. The colour was a greenish white, and the train lasted about fifteen seconds.

Independent College, Taunton, October 20

LAST Friday evening (October 19) we in Aberystwith saw a very beautiful meteor. It was ten minules past six in the evening, when as I was walking along the shore and looking seaward (west), I saw the meteor rapidly descending as a pear-shaped body of red, yellow, and purple light, increasing much in brightness till it reached about twenty feet, as it looked, from the sea surface, when it suddenly and completely disappeared. Its track seemed a part of it -a tail to it--being at first a pale golden light continuous with the body of the meteor below, extending vertically up and ending rather abruptly above.

This narrow band of light lived complete for a short time, but after one minute most of the track had become a white or slightly grey fleecy cloud about a foot broad and three yards long, as it appeared, only its central part remaining bright as a golden nucleus to the cloud.

By two minutes atmospheric currents had bent the vertical cloud into an arc, the extremities turned to the north with the bright nucleus still distinct. Gradually the nucleus disappeared, but the cloud was still visible for a quarter of an hour, when the increasing dusk of the evening helped to obscure it.

Its course appeared exceedingly rapid, and the brightness was such that a passer-by who did not see the meteor itself, said that the place was lit up "like lightning."

Weather dull and wet, but Friday evening was fine.

University College of Wales,

Aberystwith, October 20

\section{Curious Phenomenon during the Late Gale}

THE following may perhaps be of interest to your readers. At about 6.50 P.M. on the night of Sunday the $14^{\text {th }}$ inst., I was walking in a south-èasterly direction through the village of Lower Tooting, when I suddenily saw fall from the sky what looked like a huge ball of green fire. What struck me especially was its size, its vivid colour, and also the strange noiselessness of its fall. It seemed to come from a part of the sky somewhere near where Jupiter was then visible, and to fall not a hundred yards from me. This, I fear, is the most accurate information I can give. It took me so completely by surprise that I rubbed my eyes and wondered whether $\mathrm{I}$ had not been dreaming, a supposition which seemed to be supported by the indifference dispiayed by the numerous passers-by in the face of so extraordinary a phenomenon. Indeed I should hardly have thought seriously of the matter again had I not heard of a letter in the Tim $s$ last Monday, describing a very similar phenomenon observed at Brixton some twenty minutes later on the same evening. This and other reports of a like nature, which seemed to imply that the atmosphere was in a somewhat unusual condition, before and during last week's storm, led me to think it worth while to lay before you, and if it so pleases you, before the readers of NATURE, what $I$ at any rate have a strong conviction that I saw on the night in question.

G. A. M.

\section{Wine-Coloured Ivy}

THE question has been discussed of late whether the ancient Greeks had an acute and true sense of colour. I remember once to have seen the remark that Sophocles shows his want of coloursense by speaking of wine-coloured ivy. Now this really shows how true his perception of colour was. I inclose two ivy leaves which I have gathered to-day off a wall; $X$ could have gathered plenty of the same colour, which, as you will see, is claret colour.

old Forge, Dunmury, co. Antrim, October 2

\section{OUR ASTRONOMICAL COLUMN}

The Satellites of Mars.--In No. 2, $26 \mathrm{r}$ of the Astron. Nach., Prof. Asaph Hall has published his measures of both satellites from the dates of their discovery to September 16 , though the observations are not completely reduced, differential refraction and the small corrections to refer the measures to the true centre of the planet or the corrections for the gibbous phase having yet to be applied. Prof. Hall intends to make a thorough discussion of the observations taken during the present opposition, and requests other astronomers to forward to him, at Washington, copies of any they may succeed in making.

Subjoined are a few positions of the inner satellite calculated from elements which represent roughly Prof, Hall's observations from August i7 to September I6, as the following selected dates will show :-

$$
\text { Error in Pos. Error in Dist. Observed Pos. }
$$

$$
\begin{aligned}
& \text { Aug. } \begin{array}{lllllll}
17 & \ldots & -1 \cdot 1 & \ldots & +2 \cdot 1 & \ldots & 73
\end{array}
\end{aligned}
$$

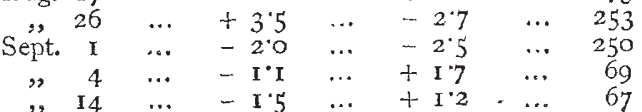

There is perhaps a sensible ellipticity of orbit. The period adopted is $7 \mathrm{~h} .39 \mathrm{~m}$. I3s.

For the outer satellite the elements used for the last ephemeris in this column have been again employed; they agree closely with measures taken by Mr. Common at Ealing on October 16 . It appears probable that $\mathrm{Mr}$. Common saw the inner satellite about 9 P.M. on October

\begin{tabular}{|c|c|c|c|c|c|c|c|c|c|c|c|}
\hline \multicolumn{7}{|c|}{ Innes Satellite. } & \multicolumn{5}{|c|}{ Outer Satellite. } \\
\hline $\begin{array}{l}\text { 8h. G.M.T. } \\
\text { Oct. } 26\end{array}$ & . & Pos. & 152 & $\ldots$ & Dist. & ${ }^{\prime \prime}$ & Pos. & $\stackrel{\circ}{9}$ & $\ldots$ & Dist. & 44 \\
\hline, 27 & $\ldots$ & 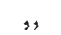 & 9 & $\ldots$ & ", & 17 & ", & 213 & $\ldots$ & , & $3^{I}$ \\
\hline 28 & .. &, & 69 & $\ldots$ & " & 22 & ", & $25^{6}$ & $\cdots$ & $"$, & 55 \\
\hline 29 & $\ldots$ & , & 37 & $\ldots$ & $"$ & 12 & $\because$, & 324 & $\cdots$ & , & 22 \\
\hline 30 & $\ldots$ & , & 306 & $\cdots$ & , & IO &, & 64 & ... & $"$, & $5 x$ \\
\hline,$" 3$ I & $\ldots$ &, & 263 & $\ldots$ & , & 19 & , & 103 & $\cdots$ &, & 3.3 \\
\hline Nov. I & $\ldots$ & ," & 242 & ... & , & 20 & $n$ & 224 & ... & ", & 34 \\
\hline, & $\ldots$ &, & IO4 & $\cdots$ & , & 9 & " & 262 & $\cdots$ & , & 47 \\
\hline
\end{tabular}
17 , the calculated and estimated positions sufficiently according. 